\title{
Mobile Learning: A Topography and Research
}

\author{
Simon W. W. So
}

\begin{abstract}
A topography of mobile learning and the author's research work in the three phases of mobile learning are delineated in this paper. The aim is to provide the diachronic summary of the author as well as other researchers in these three phases of mobile learning namely the focus on devices, learning outside classroom and the mobility of learners. The research covers in many domains of mobile learning. A brief discussion on the salient characteristics of mobile learning and the issues will be provided. Hopefully, the experience learnt can be valuable for other researchers in the field.
\end{abstract}

Index Terms-Mobile learning, XTHML-MP on WAP phones, SMS with GSM modems, QR-Codes with smartphones.

\section{INTRODUCTION}

In the book titled 'Mobile Learning: Structures, Agency, Practices', Pachler et al. [1] start out the topography of mobile learning with a diachronic overview using a structure proposed by Mike Sharples [2], [3]. Sharples outlined three phases of mobile learning characterized by: 1) a focus on devices, 2) a focus on learning outside the classroom, and 3) a focus on the mobility of the learner. According to Pachler et al. [1], 'it seems important to stress that the respective foci are not exclusive to any one phase, but that each phase is arguably characterized by an emphasis on one focal point. For example, of late we detect a resurgence of interest in devices with the introduction of new devices, such as Apple ... and phones that run Google's Android...'. Providing a parallel discussion, the research work conducted by the author of this paper in this field at all three phases will be discussed together with the examples described in Section II. The salient characteristics of mobile learning and its issues will be briefly discussed in Section III.

\section{MOBILE LEARNING: A TOPOGRAPHY AND RESEARCH}

\section{A. The First Phase of Mobile Learning: A Focus on Devices}

This phase is characterized by the focus on mobile devices (e.g., PDAs, tablets and mobile phones), which can be used in an educational context for instruction and training. These devices can function as personal response systems, data logging devices, and handheld e-learning devices. For example, two ambitious projects conducted by MacFarlane and her colleagues [4], [5], namely, 'Learning2Go' in

Manuscript received October 19, 2013; revised December 20, 2013. This work was supported in part by the Department of Mathematics and Information Technology, Hong Kong Institute of Education under a number of internal research grants and funding.

Simon W. W. So is with the Hong Kong Institute of Education, 10 Lo Ping Road, Tai Po, New Territories, Hong Kong (e-mail: swwso@ied.edu.hk).
Wolverhampton and 'Hand e-learning' in Bristol, have enabled students in a year group and their teachers to have individual mobile devices (i.e., 1:1 personal ownership of mobile devices). Although the researchers recognize the value of incorporating mobile devices in teaching and learning, they identified the following key problems: 1) the schools lacked the needed infrastructure; 2) the preliminary training of teachers was rushed; and 3) the subject selected for the promotion of the use of the device was science and science teachers were too preoccupied with a major change in the science curriculum of GCSE at the time. The researchers also found that the introduction of 1:1 ownership of mobile devices is more problematic and complex in secondary than in primary schools.

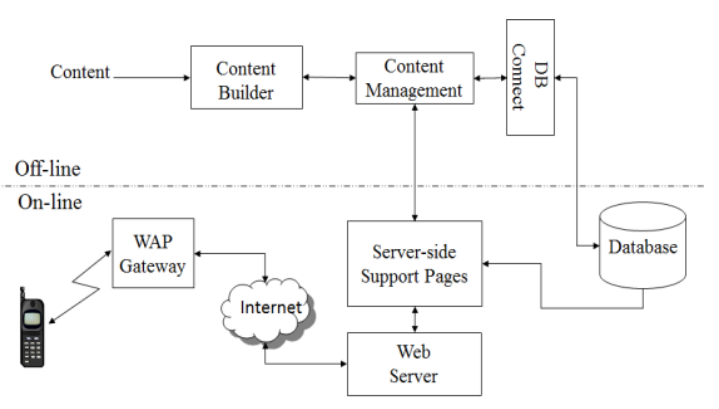

Fig. 1. The system architecture for the three applications.
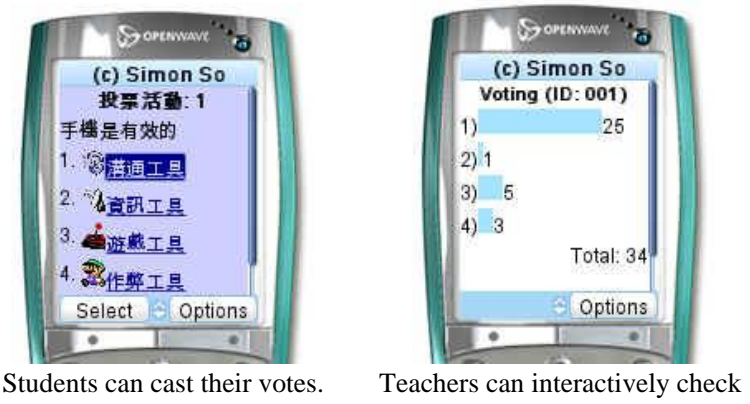

Fig. 2. A voting activity.

Bradley et al. [6], [7] explored the deployment of multimedia learning objects for mobile phones. Internet-based 'reusable learning objects' (RLOs) were readjusted to fit Nokia 70/90 smartphones. Learning support included 'basic guides' and 'self-tests'. Positive feedbacks were received from the students on the evaluation of RLOs like sports science. One possible criticism of the learning object approach is that it simply replicates the desktop experience [1]. It does not take advantage of the salient features of smartphones.

In 2007, the author designed and developed a series of $\mathrm{m}$-learning activities for a group of pre-service IT teachers [8]. Three applications were designed and programmed using the XTHML-MP/ WAP 2.0 gateway technologies and supported by server-side web technologies of PHP and MySQL. Fig. 1 outlines the system architecture to support 
applications over mobile devices. The research was aimed at providing the opportunities for the teachers to explore this new trend in teaching and learning and to find out their acceptance of this approach. Fig. 2 demonstrates a voting activity. A "15/16" interactive game is shown in Fig. 3. Fig. 4 illustrates an assessment exercise. These were tested on Nokia handsets. Based on the findings of this study, majority of the surveyed respondents were very liberal and interested to use mobile phones for teaching and learning.

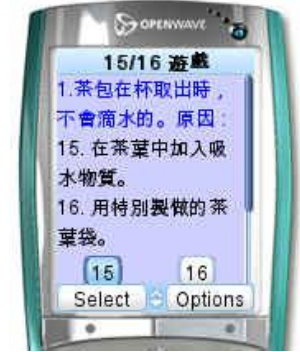

A question from the " $15 / 16$ " interactive game.

Fig. 3. A " $15 / 16$ " interactive game.

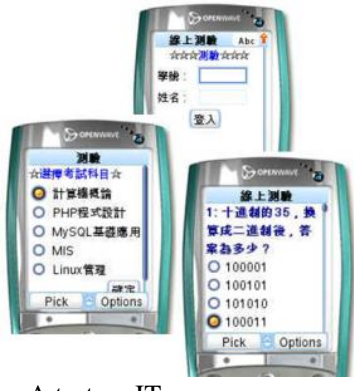

A test on IT.

Fig. 4. Assessment.

\section{B. The Second Phase of Mobile Learning: A Focus on Learning Outside the Classroom}

This phase is characterized by learning outside the classroom. The learning activities may include field trips, museum visits, and bit-size learning initiatives. Recent mobile devices offer powerful connectivity and positioning information, thereby allowing location-aware activities and context-aware learning through these devices. For example, the 'Skattjakt' (Treasure Hunt) project developed at Vaxjo University is a mobile game designed to encourage young people to engage in physical activities by solving a mystery surrounding a castle built on the university's campus [9]. At each location on the campus, students would receive a clue that is needed to find a four-digit code, which should then be entered into the phone. After which, they receive a question. If they answer the question correctly, they would receive a clue for the next location. The objective of the game is to be the first person to reach the seventh and final location. The researchers claimed that their research would bridge the gap between learning in informal and formal settings.

SMS-based learning is also important in this phase of mobile learning. According to Pachler et al. [1], SMS communications and alerts have 'the potential to reach parts of the world that traditional media, including the computer-based internet, is not able to reach'. SMS texting on mobile phones has great potential in outdoor and informal education [10]. Numerous SMS projects for teaching and learning have been reported in the literature in the last 10 years. A comprehensive review can be found in the study by the author [11]. In 2009, an SMS-based teaching and learning system was developed. Fig. 5 shows a minimal setup of the system. A Wavecom compatible GPRS/GSM modem was used. Fig. 6 demonstrates the sequence of extended AT commands to drive the modem. The system is capable of supporting teaching, learning, and administrative activities via the SMS technology.

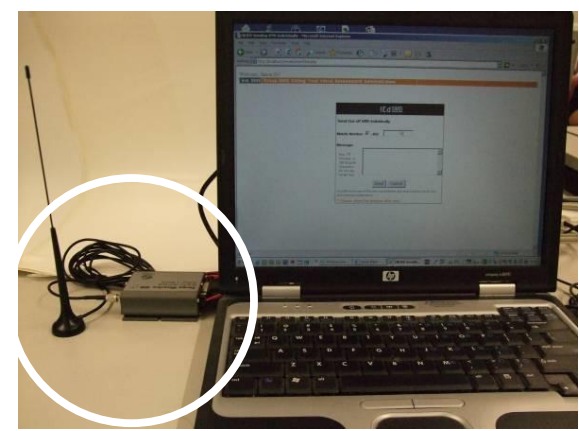

Fig. 5. The SMS-based system with the GSM modem can support learning inside and outside classroom.

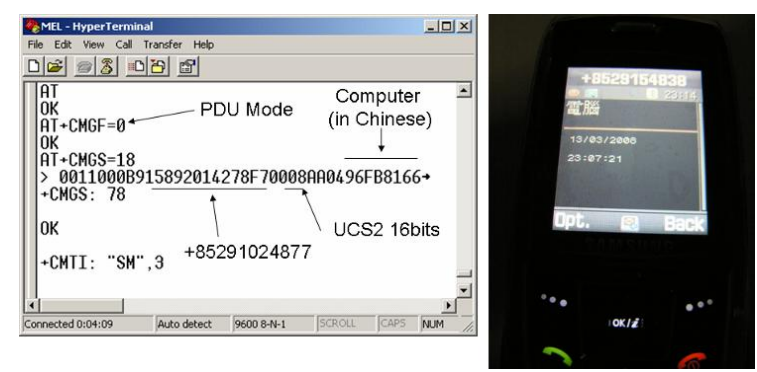

Fig. 6. A demonstration using extended at commands to drive the GSM modem.

The SMS-based teaching and learning system allows teachers to send individual SMS messages directly or group SMS messages from the mobile numbers stored in the system. Fig. 7 illustrates the web interface to support this feature.

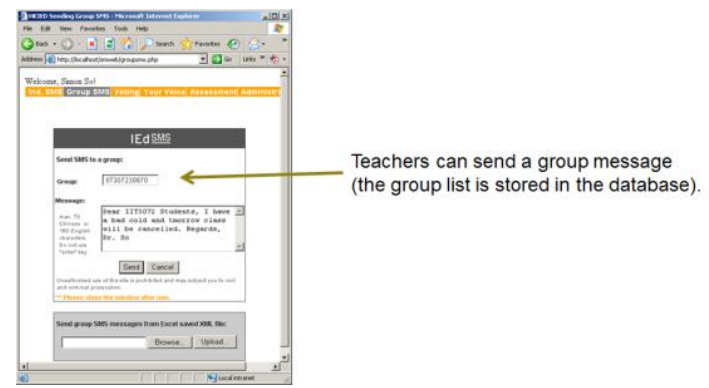

Fig. 7. Communication and administrative support: sending an individual or group SMS teaching and learning messages.

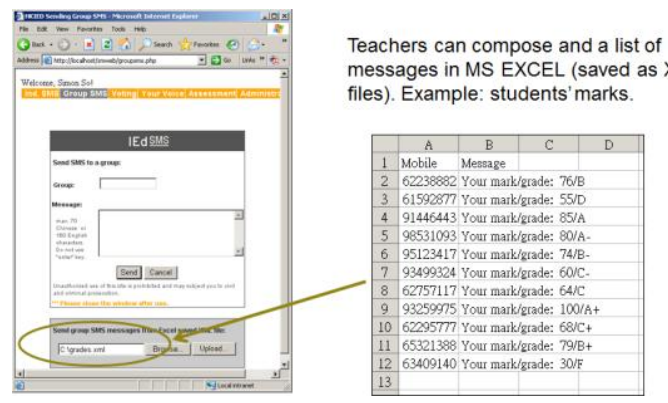

Fig. 8. Communication and administrative support: sending students' marks and grades. 
Teachers can also send group SMS messages to each student of a class stored in a MS Excel XML file. This is a very efficient way to send SMS messages such as marks and grades to each student of a class as shown in Fig. 8.

To support student-centered learning, brainstorming activities can be adopted by teachers. Students can send their ideas and opinions using their mobile phones to the system as illustrated in Fig. 9. Their names with their messages can be shown on the web or anonymously to promote active participation.
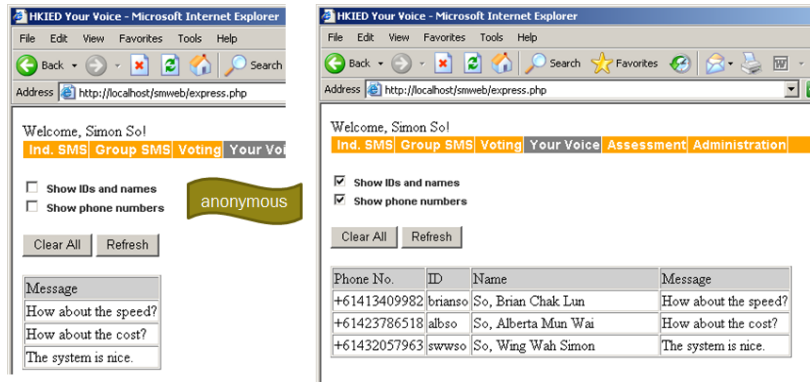

Fig. 9. Teaching and learning support: brainstorming activities.

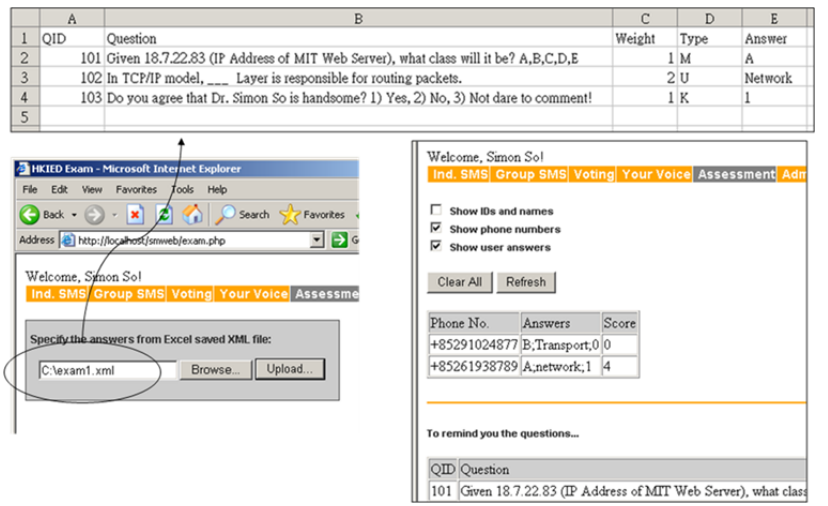

Fig. 10. Teaching and learning support: assessment activities.

Assessment is a broad process of evaluating how effectively learning is occurring. It is an integral part of any teaching and learning activity. It influences student motivation and learning. The SMS-based teaching and learning system provides facilities for teachers to carry out assessment. Teachers can compose item banks in Excel. The system supports a variety of question types such as multiple-choices, short answers and a sequence of touch-key answers. Fig. 10 demonstrates the process.

\section{The Third Phase of Mobile Learning: A Focus on Mobility of the Learner}

The third phase is characterized by the focus on the mobility of the learner, the design or the appropriation of learning spaces, and the informal learning and lifelong learning. Mixed reality learning, context-sensitive learning, and ambient learning are the focus of this phase. These are emerging topics in mobile, ubiquitous, and pervasive learning. Many interesting projects are being reported in these areas. The 'MyArtSpace' project by M. Sharple [3], the 'CONTSENS' [12] project by European Commission's Mobile Learning, the 'Urban Education for Trainee Teachers' project implemented at Metropolitan University [13], and the 'Mobile Augmented Reality Applications' project from Nokia [14] are some of the highlighted projects [1].
In many of these projects, QR codes can be used to support mixed reality, context-sensitive, and ambient learning. A QR code is capable of holding 7,089 numeric characters, 4,296 alphanumeric characters, 2,953 binary bytes, 1,817 Kanji characters or a mixture of them. Coupled with a moderate equipped mobile device, it opens up a new horizon for many applications in the commercial world as well as in education. A QR code can be read even it is somewhat distorted by either being tilted or on a curved surface by alignment patterns and timing patterns as shown in Fig. 11. The error correction capability against dirt and damage can be up to $30 \%$. Before we go on to discuss the use of this technology, we must first obtain a common decoder such as i-nigma [15]. The decoder can scan codes embedded with a variety of information. Table I illustrates the different natures of QR codes that can be processed by the decoder. Beside the typical use of encoding URLs and plain-texts, QR codes can be used to directly insert events onto the calendar app of any smartphone. The decoder can open a map with embedded geo coordinates. QR codes are very useful for education and personal use.

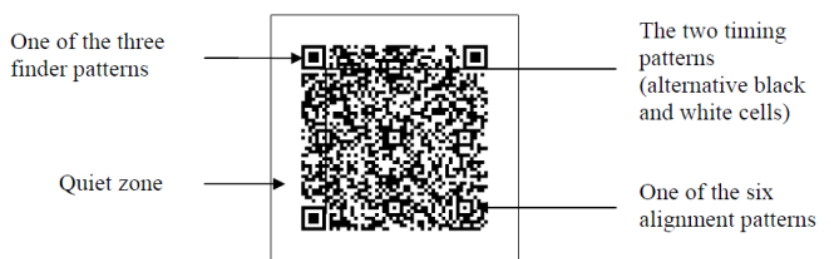

Fig. 11. The finder patterns, timing patterns, alignment patterns and the quiet zone of a QR code.

TABLE I: DIFFERENT NATURES OF QR CODES CAN BE PROCESSED BY A DECODER

\begin{tabular}{|c|c|c|}
\hline $\begin{array}{l}\text { Text: any textual } \\
\text { information can be } \\
\text { embedded. }\end{array}$ & $\begin{array}{l}U R L: \text { a link to } \\
\text { www.iacsit.org }\end{array}$ & $\begin{array}{l}\text { Event: ICIET } 2014 \\
\text { (dates and location } \\
\text { can be directly } \\
\text { inserted to any } \\
\text { smartphone's } \\
\text { calendar) }\end{array}$ \\
\hline 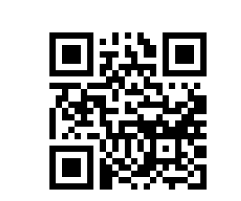 & 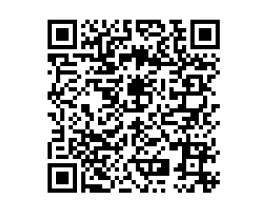 & 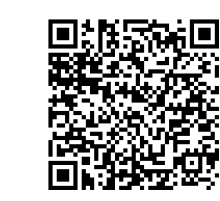 \\
\hline $\begin{array}{l}\text { Geo Location: } \\
\text { Mercure Melbourne } \\
\text { Treasury Garden's } \\
\text { coordinates; } \\
\text { (directly map to } \\
\text { Google Map etc.) }\end{array}$ & $\begin{array}{l}\text { Contact: can store the } \\
\text { information directly } \\
\text { into the address book } \\
\text { or call the phone } \\
\text { number directly. }\end{array}$ & $\begin{array}{l}S M S \text { can send the } \\
\text { message to the } \\
\text { destined phone } \\
\text { number directly }\end{array}$ \\
\hline
\end{tabular}

The author recently conducted a research project with $\mathrm{QR}$ codes [16]. Three broad fields were experimented: 1) 'Math Trail' in the area of outdoor learning activities (Fig. 12), 2) 
'English listening exercise' in the area of self-directed multimedia learning activities (Fig. 13), and 3) 'self-evaluation exercise' in the area of self-assessed tasks (Fig. 14). The experiment was conducted in two primary schools in Hong Kong.

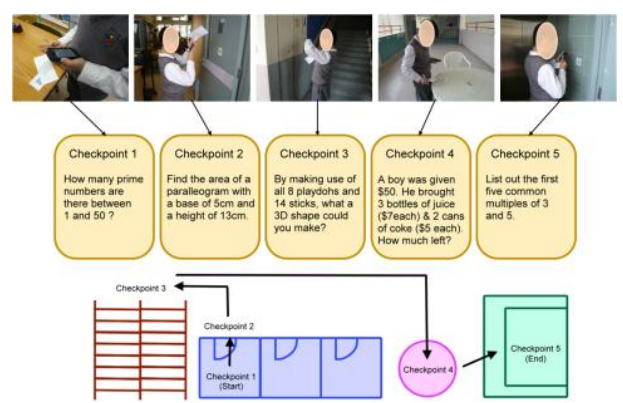

a) A primary student participates in a math trail activity.

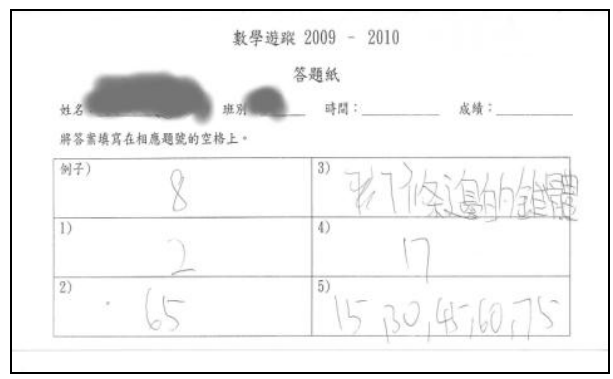

b) The worksheet was prepared by the student in a).

Fig. 12. An outdoor activity: math trail.

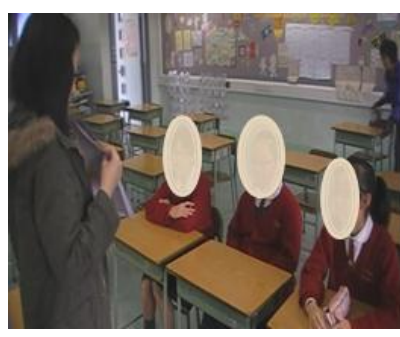

a) The teacher explained the worksheet.

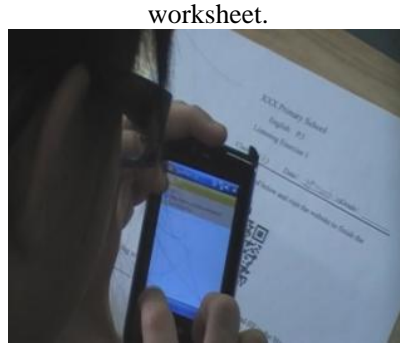

c) The phone converted it into a Youtube URL to be clicked. Fig. 13. An English listening exercise.

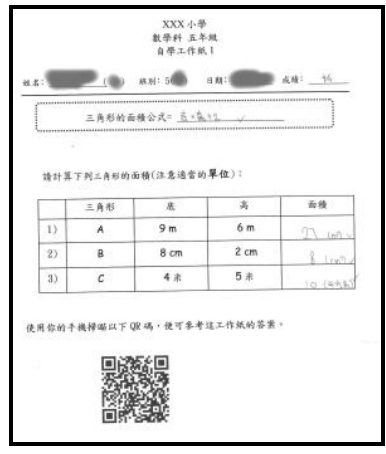

a) The worksheet of a P.5 math self-evaluation exercise.

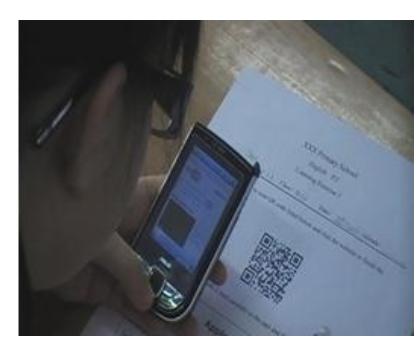

b) A student snapped the QR code on the worksheet.

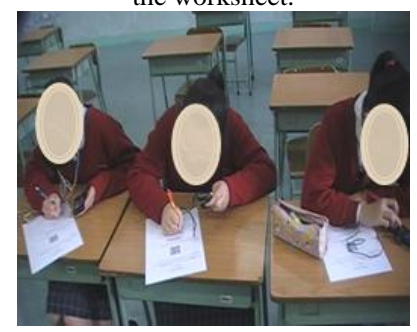

d) The students carried out the istening exercise.

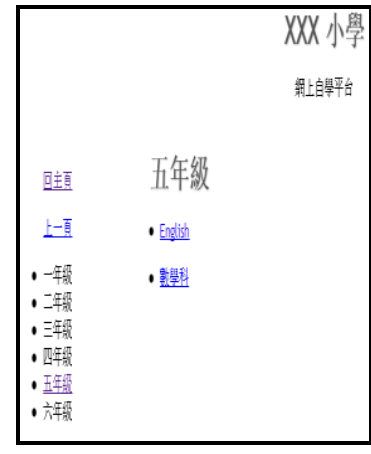

b) By scanning the $\mathrm{QR}$ code, th student can quickly check their answers online.
Fig. 14. A self-evaluation exercise.

\section{DISCUSSION}

The emergence and rapid development of mobile and wireless technologies change the society significantly. Recent statistics show that Hong Kong has one of the highest mobile penetration rates peaked at $233 \%$ as of June 2013 [17]. That means, on average, each person has 2.3 mobile devices in Hong Kong. These devices are very useful for education. However, if you ask any expert in the field for a definition of mobile learning, you will get different answers. Nevertheless, the salient characteristics of the education technology on mobile learning include 1) mobility, 2) portability, 3) ubiquity and 4) pervasiveness. Coupled with feature-rich, multimedia-rich and web-enable mobile devices, the technology plays a pivotal role in learning as we can see from the above mentioned research and development in curriculum planning, pedagogies, formal/informal learning, independent/collaborative learning, active/deep learning and many more.

While we can creatively employ mobile devices for teaching, learning and administrative needs, a number of issues concurrently emerge. These include 1) underprivileged students could not afford for expensive mobile devices, 2) mobile devices for younger children can lead to security, safety and discipline issues in school and at home, 3) a prolong use of mobile devices create a number of health-related issues such as neck-shoulder pain, sore single fingers, sore eyes and many more, and 4) addictiveness to these devices creates a range of personal and social problems with friends and families.

\section{CONCLUSION}

This paper aims to provide the topography of mobile learning. With reference to the three phases of mobile learning proposed by Mike Sharples [2], [3], the author demonstrated there are a number of creative uses on mobile devices for education technology. Moving from the focus of mobile devices to the mobility of learning, the research development in the field of mobile learning is exciting. Feature-rich mobile devices offer excellent opportunities in many domains of mobile learning and education. At the same time, many issues emerge and some issues are mentioned above. I hope the research presented in this paper can arouse interested readers and trigger their thought and further exploration in the field of mobile learning.

\section{REFERENCES}

[1] N. Pachler, B. Bachmair, and J. Cook, Mobile Learning: Structure, Agency, Practices, NY: Springer, 2010.

[2] M. Sharples, "Future Gazing for Policy Makers," in Proc. Becta Seminar, BT Government Innovation Center, London, UK, March, 28, 2006.

[3] M. Sharples. (2007). Big Issues in Mobile Learning: Report of a Workshop by the Kaleidoscope Network of Excellence. LSRI, University of Nottingham. [Online]. Available: http://mlearning.noe-kaleidoscope.org/repository/BigIssues.pdf

[4] A. McFarlane, N. Rouche, and P. Triggs, Mobile Learning: Research Findings, UK: Becta, 2007.

[5] A. McFarlane, P. Triggs, and W. Yee, Researching mobile learning Interim report to Becta Period: April-December, UK: Becta, 2008

[6] C. Bradley, R. Haynes, T. Boyle, J. Cook, and C. Smith, "Multimedia Learning Objects for Mobiles," presented at the IADIS International Conference Mobile Learning, Lisbon, Portugal, July 5-7, 2007. 
[7] C. Bradley, R. Haynes, T. Boyle, J. Cook, and C. Smith, "Design and development of Multimedia Learning Objects for Mobile Phones," in Mobile Learning: Transforming the Delivery of Education and Training, M, Ally, Ed., Edmonton, Alberta: Athabasca University Press, 2009.

[8] S. So, "A Study on the Acceptance of Mobile Phones for Teaching and Learning with a Group of Pre-service Teachers in Hong Kong," Journal of Educational Technology Development and Exchange, vol. 1 , no. 1, pp. 81-92, 2008.

[9] CeLeKT. Skattjakt Treasurehunt. Center for Learning and Knowledge Technologies. Vaxjo University. [Online]. Available: http://www.celekt.info/projects/show/15.

[10] J. Traxler, "Case studies: Introduction and overview," in Mobile Learning: A Handbook for Educators and Trainers, A. Kukulska-Hulme and J. Traxler Eds., London: Routledge, 2005, pp. 70-75.

[11] S. So, "The Development of a SMS-based Teaching and Learning System," Journal of Educational Technology Development and Exchange, vol. 2, no. 1, pp. 113-124, 2009.

[12] Ericsson. (2008). Using Wireless Technologies for Context Sensitive Education and Training. Ericsson (CONTSENS). [Online]. Available: http://www.ericsson.com/ericsson/corpinfo/programs/using_wireless_ technologies_for_context_sensitive_education_and_training/

[13] C. Smith, J. Cook, and C. Bradley, "Engineering suitable content for context sensitive education and vocational training (CONTSENS)," presented at Conference on Handheld Learning, London, October $13-15,2008$

[14] MARA. (2012). The Mobile Augmented Reality Project. Nokia Research Center. [Online]. Available: http://research.nokia.com/page/219

[15] 3GVision. Download i-nigma Reader. [Online]. Available: http://www.i-nigma.com/Downloadi-nigmaReader.html.

[16] C. Law and S. So, "QR Codes in Education," Journal of Educational Technology Development and Exchange, vol. 3, no. 1, pp. 85-100, 2010.
[17] OGCIO. Hong Kong: The Facts. Office of the Communications Authority. Hong Kong Special Administrative Region Government. [Online]. Available: http://www.gov.hk/en/about/ abouthk/factsheets/docs/telecommunications.pdf.

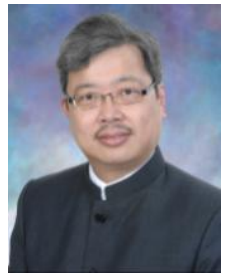

Simon W. W. So is a native of Hong Kong and an Australian citizen. He holds $\mathrm{BSc}$ in computer engineering from University of Alberta (1985), PGDE in Computer and Information Technology Education from Baptist University (2007), Master of Education from Deakin University (2008), Master of Statistics from University of Hong Kong (2010), and $\mathrm{PhD}$ in Computer Science from Victoria University (2000).

$\mathrm{He}$ is currently a faculty member in Information Technology at the Hong Kong Institute of Education, Department of Mathematics and Information Technology. He has many years of working experience. He has held various technical and managerial positions in IT industry in the past. He has published research articles widely and his publications include books chapters and articles in journals, professional series and international conferences. His services to the international research community include serving as Editorial Board Member, Program Committee Member, Organizing Member, Technical Expert and Regional Director of refereed journals, international conferences and professional organizations in Australia, Europe, Asia and US. He served as External Examiner for a number of doctorial and master research dissertations internationally. $\mathrm{He}$ also serves as the subject member and provides consultation works for government bodies in education. He was a member of the Curriculum Development Council Committee on Technology Education in Hong Kong and was the setter of public examination papers for Hong Kong Examination and Assessment Authority in many years.

His research interests include Mobile Learning, Game-based Learning, Educational Use of Multimedia and Internet Technologies, Multimedia Information Retrieval and Web Standards. 